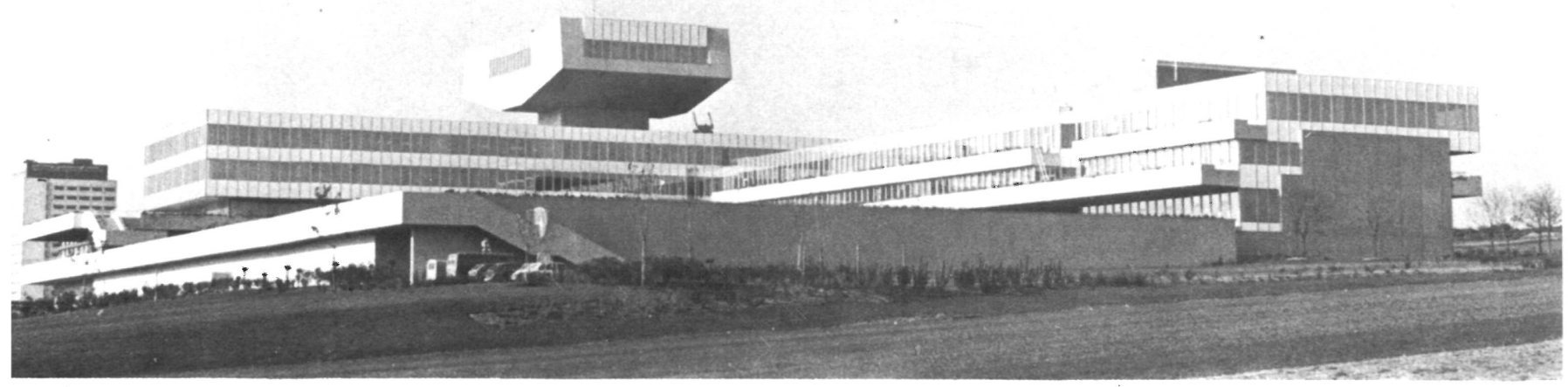

\title{
Edificio de Oficinas en Viena - Austria
}

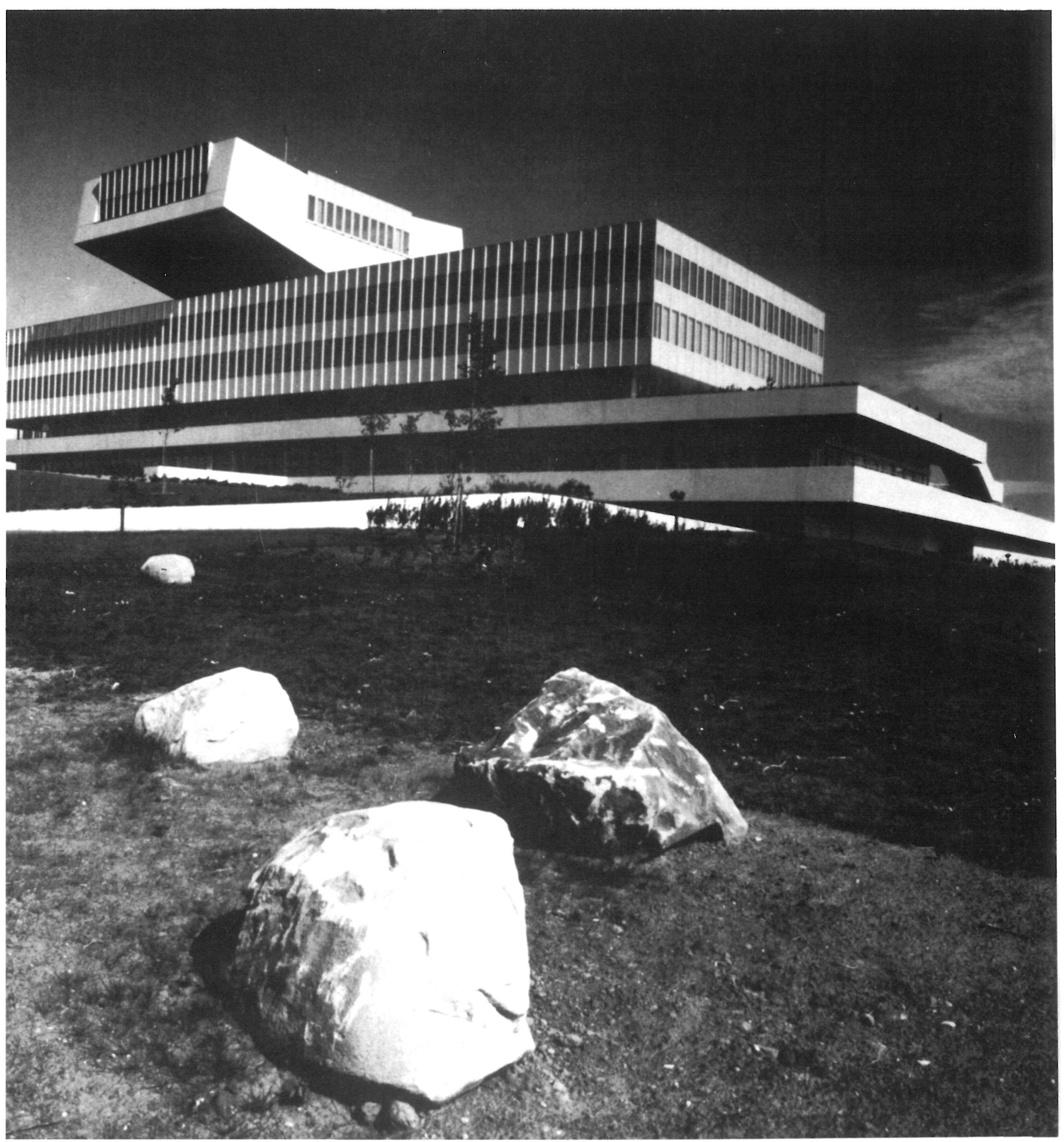




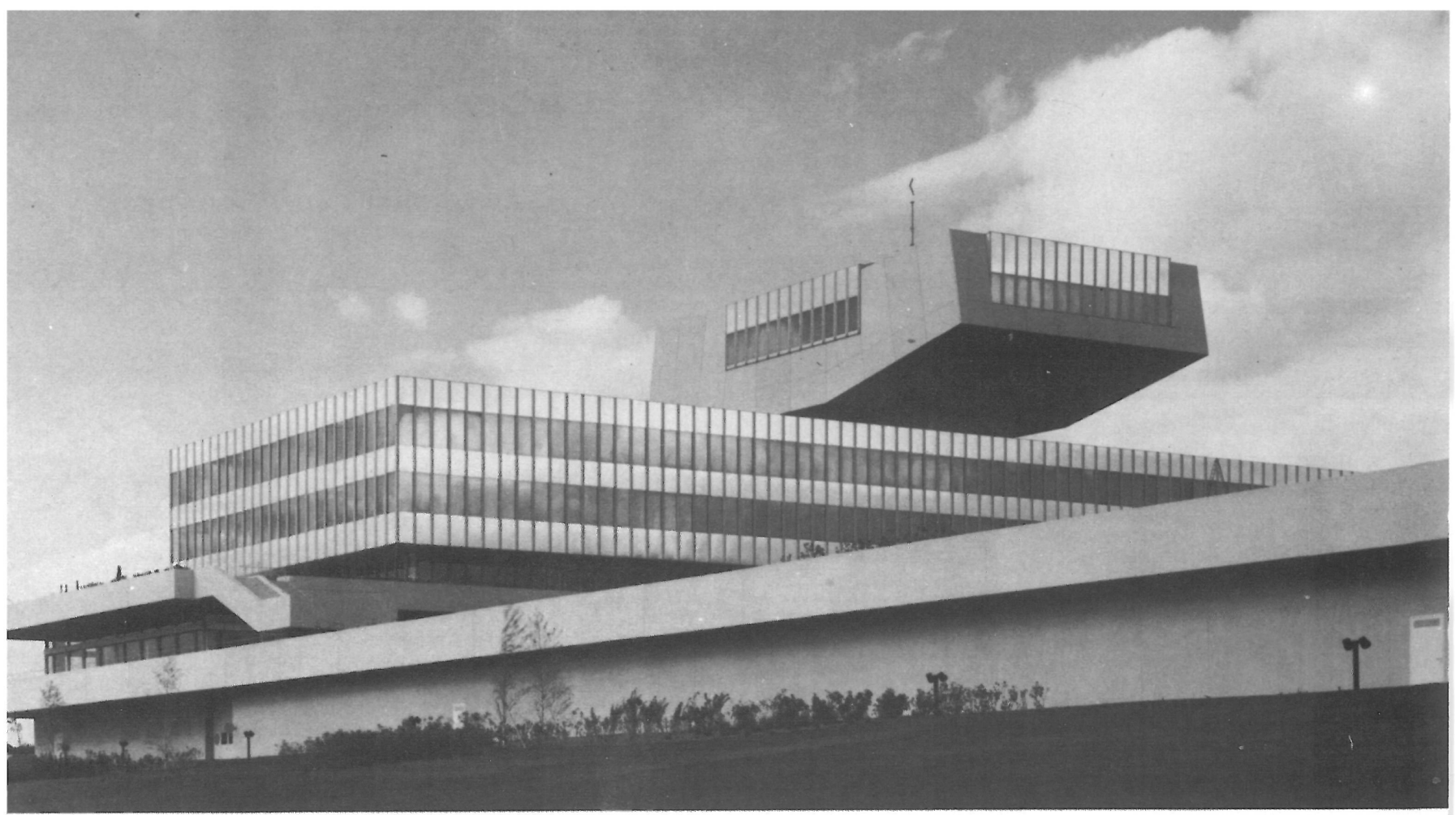

PROF. GEORG LIPPERT, arquitecto

\section{sipnosis}

Las oficinas centrales de la Austrian Alrlines están emplazadas en las proximldades de Viena, en una amplia parcela de $32.700 \mathrm{~m}^{2}$, de los que la construcción ocupa 13.000 , destinados los restantes a jardines y explanadas.

El edificlo consta de cuatro plantas de altura máxima y un amplio sótano destlalura máxicios y aparcamientos. En nado a las plantas ouperores y oficinas taurate y cafetería par cllentes, y cotaurante y cafotorla para cllentes, y comedor,

En el planteamiento arquitectónico destaca una torre de $32 \mathrm{~m}$ de altura, concetaca una torre de 32 me de altura capaz de su como distancia, la naturaleza de la sugerir, a distancia, la nála de la compañí.
Para el emplazamiento de las oficinas centrales de la compañía austríaca de aviación (Austrian Airlines), se escogió una parcela de $32.700 \mathrm{~m}^{2}$ situada en la ladera de un monte, donde la nueva construcción queda incorporada a un conjunto urbanístico preexistente integrado por un balneario y un hotel. El complejo está servido por la proyectada autopista que permite el enlace terrestre directo y rápido con Viena y con el aeropuerto Viena-Śchwechat. En la elección del terreno no sólo intervino esta última circunstancia - la rapidez de las comunicaciones con Viena y con el aeropuerto-sino también las agradables condiciones climáticas del lugar.

La construcción se configuró en forma de «L", delimitando con su diseño un gran patio protegido contra el viento, circunstancia que permite a los usuarios un buen aprovechamiento de los paseos y descansos al aire libre.

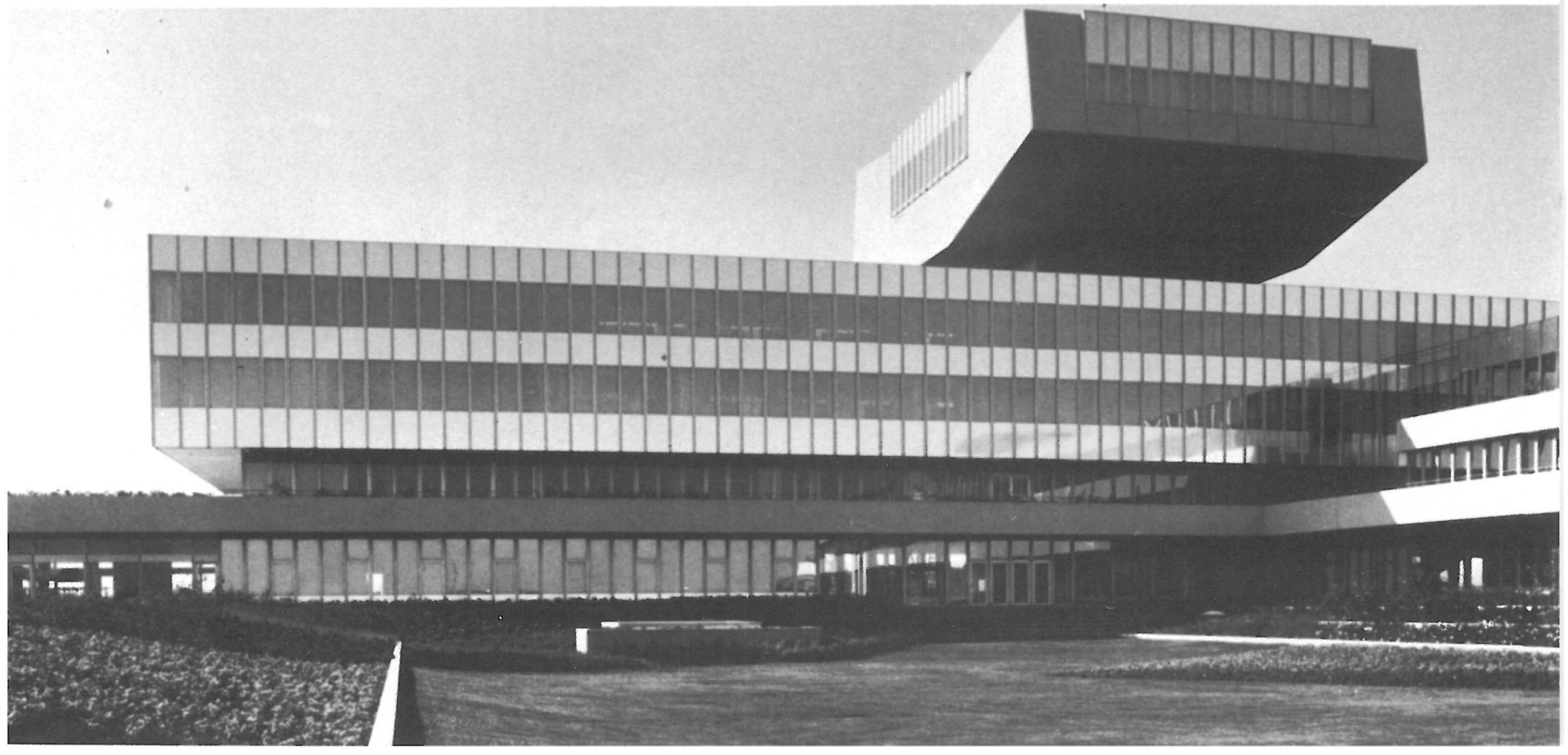




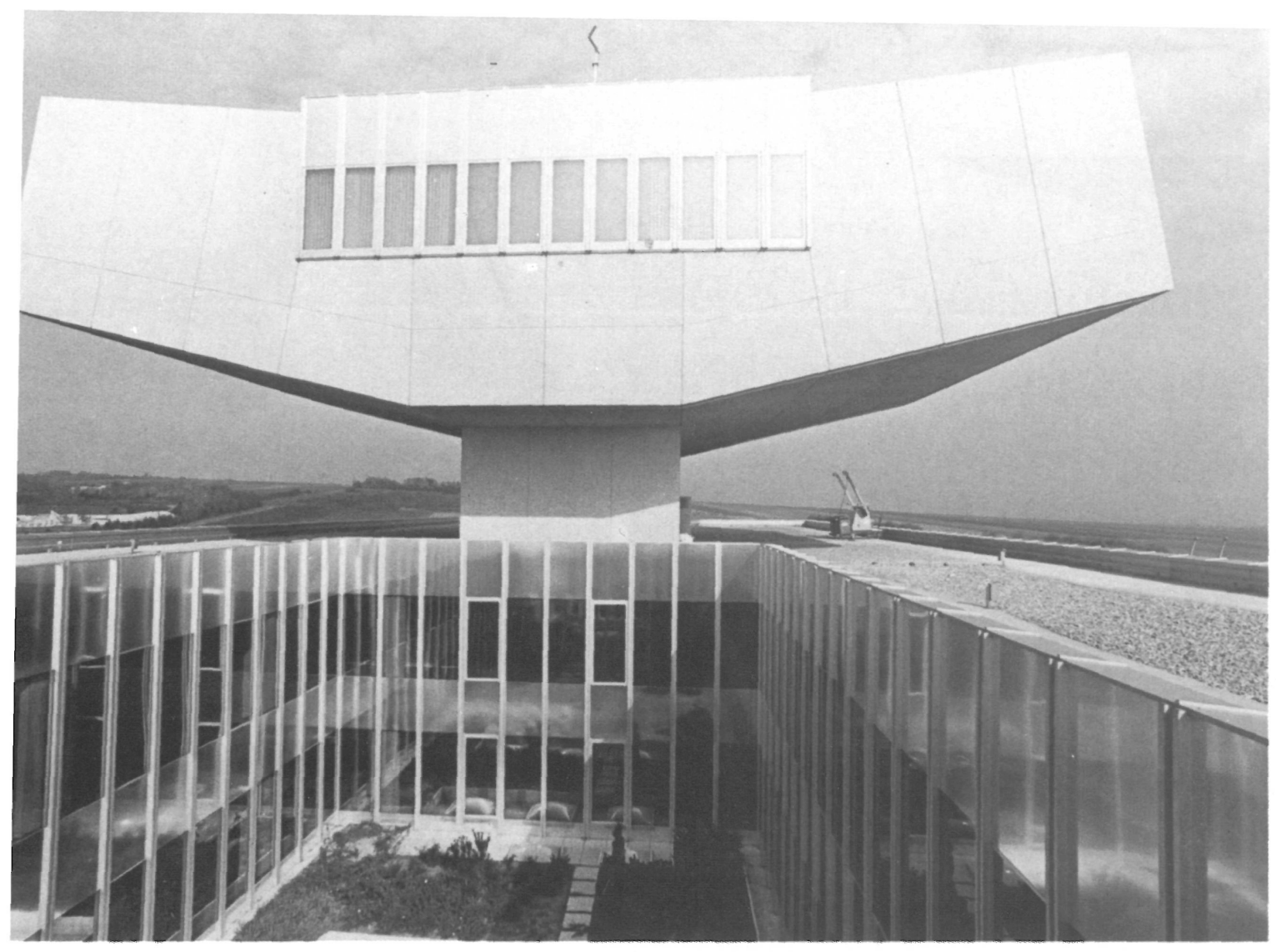

La obra dispone de cuatro niveles, sobre rasante, evitando el exceso de altura a fin de permitir la continuidad del paisaje y la integración armónica de la nueva construcción con el entorno natural. En compensación a la escasa altura, la construcción se extiende en superficie, ocupando $13.000 \mathrm{~m}^{2}$ de terreno, y dejando los casi $22.000 \mathrm{~m}^{2}$ restantes dedicados a espacios libres ajardinados, explanadas y vías de paso.

Con el fin de dotar al edificio de un elemento arquitectónico distintivo, que de alguna manera simbolizara la actividad de la compañía, se erigió una torre singular de $32 \mathrm{~m}$ de altura, sobre el acceso principal, destinada a albergar al cuerpo ejecutivo. Asimilable a una torre de control, este cuerpo sobresaliente se convierte en signo de identificación que puede ser visto desde lejos, tanto desde tierra como desde el aire.

El brazo norte de la «L» está conformado por una construc-

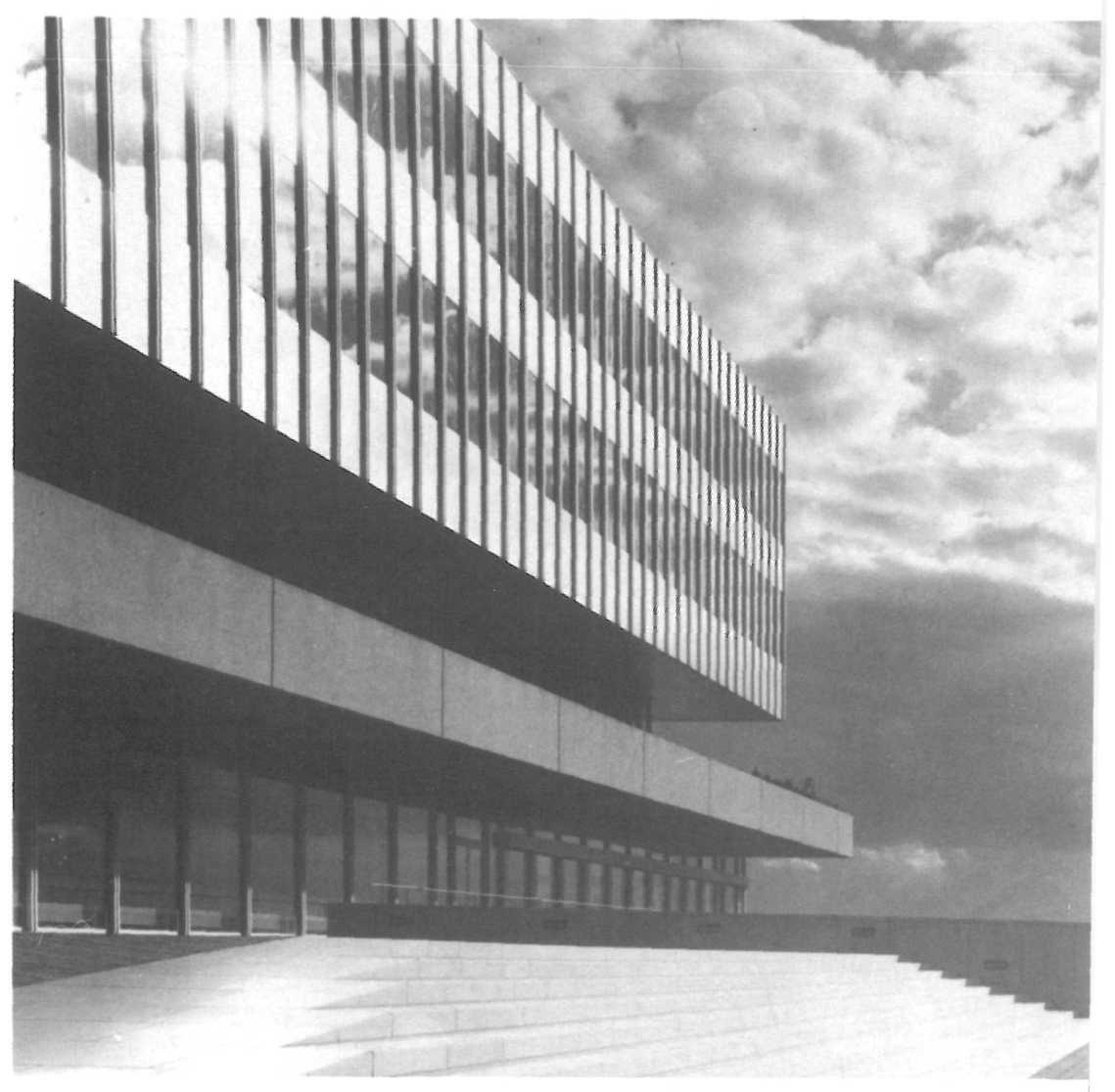



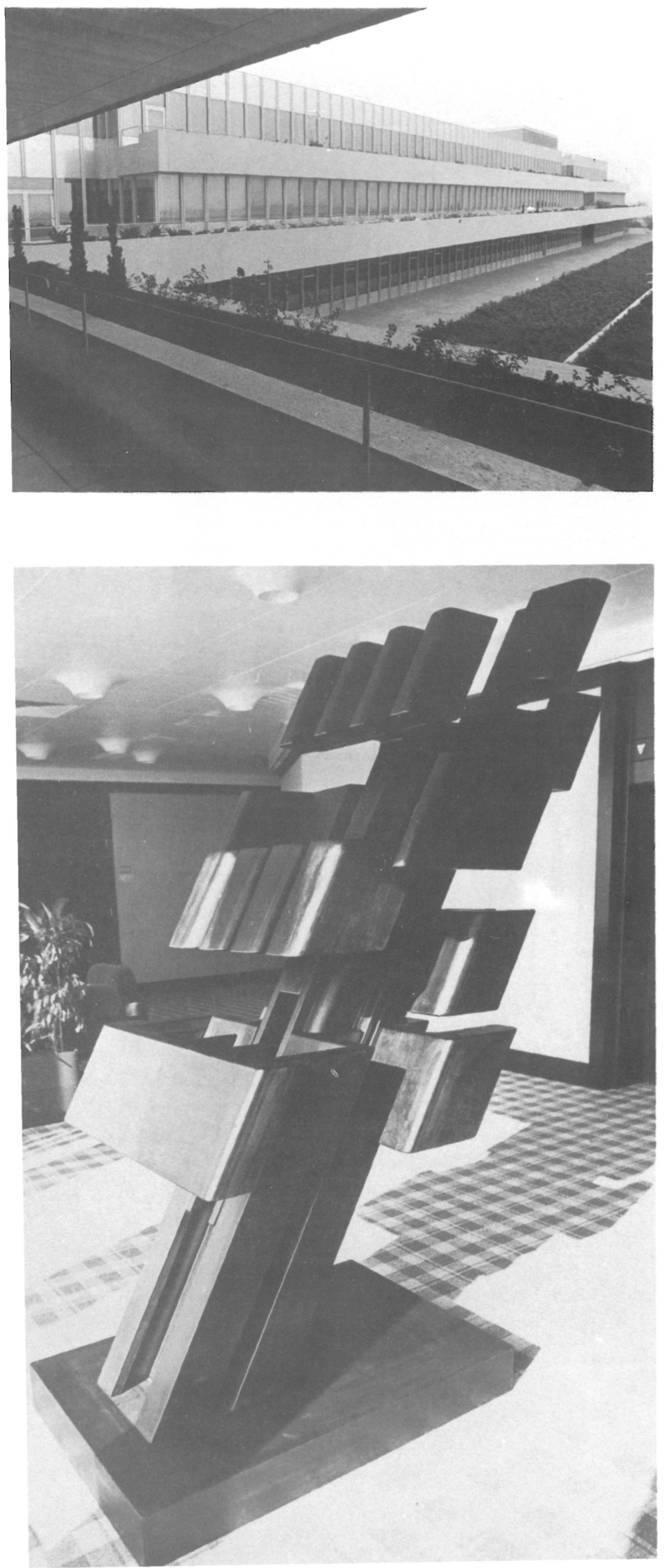

ción de tres plantas, escalonadas formando terrazas orientadas hacia el patio central. Dichas terrazas constituyen un estadio intermedio agradable entre el espacio interior o ámbito de trabajo y el paisaje circundante.

Exteriormente las fachadas del edificio han sido tratadas con elementos de aluminio, de diseño vertical, en módulos de $1,25 \mathrm{~m}$. Unos $2.700 \mathrm{~m}^{2}$ de paneles de aluminio brillante alternan con $4.600 \mathrm{~m}^{2}$ de cristales tintados para protección solar. La torre, por el contrario, está revestida con prefabricados de hormigón blanco, al igual que los antepechos corridos de la planta baja. Para contrarrestar con estos materiales, la explanada y las terrazas del jardín se pavimentaron con piezas de color rojizo.

La estructura se resolvió, básicamente, en hormigón armado, apoyando toda la obra en zapatas y zanjas corridas, a excepción de la torre que, por la naturaleza de las cargas, fue cimentada sobre pilotes. El proceso constructivo de esta última constituye un dato curioso y digno de mención, ya que la estructura volada, de $1.400 \mathrm{t}$ de peso, fue prefabricada en hormigón pretensado y elevada a su posición final, sobre la caja de ascensores y escaleras, mediante gatos elevadores, a razón de $7 \mathrm{~m}$ al día. 


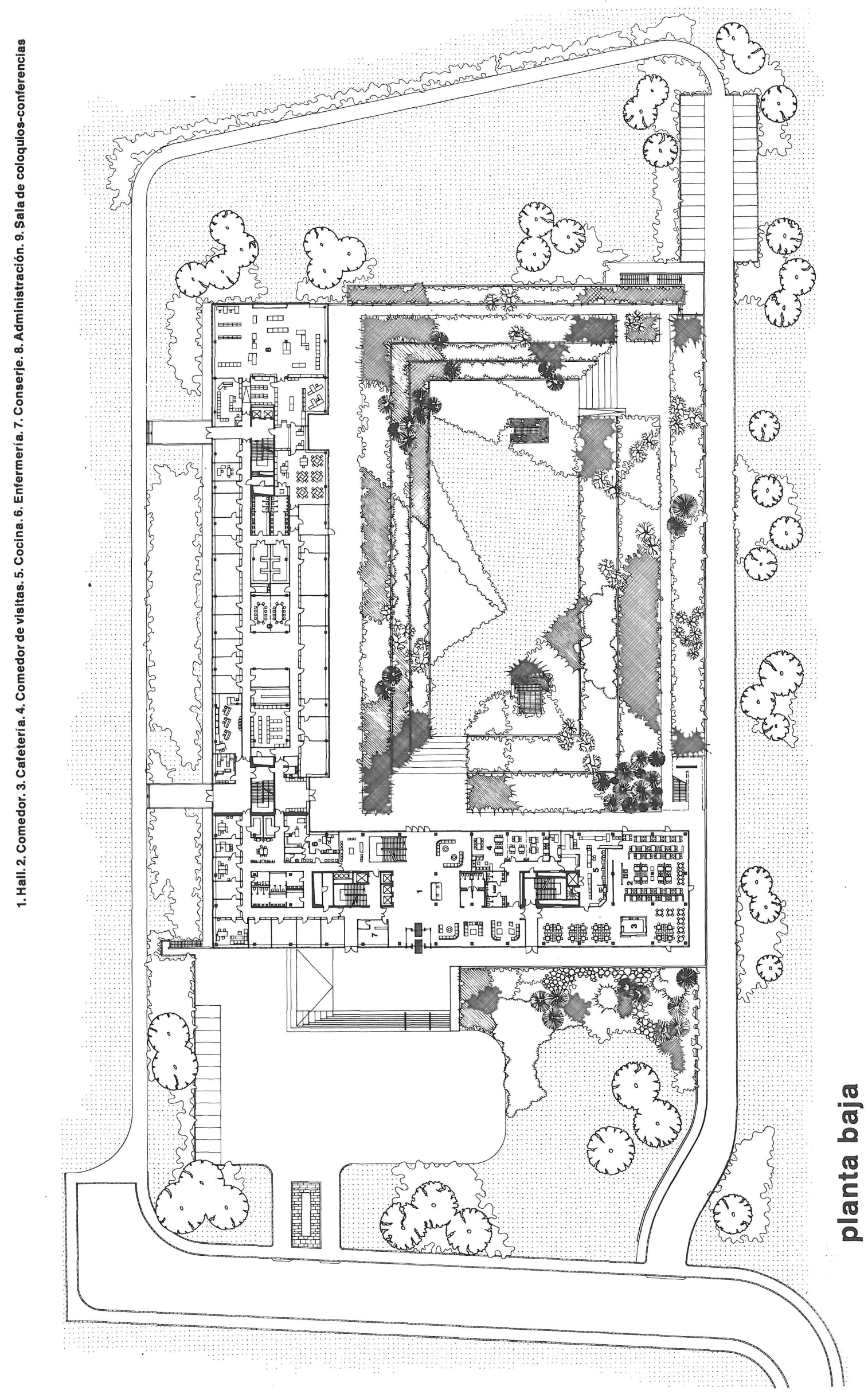




\section{planta primera}

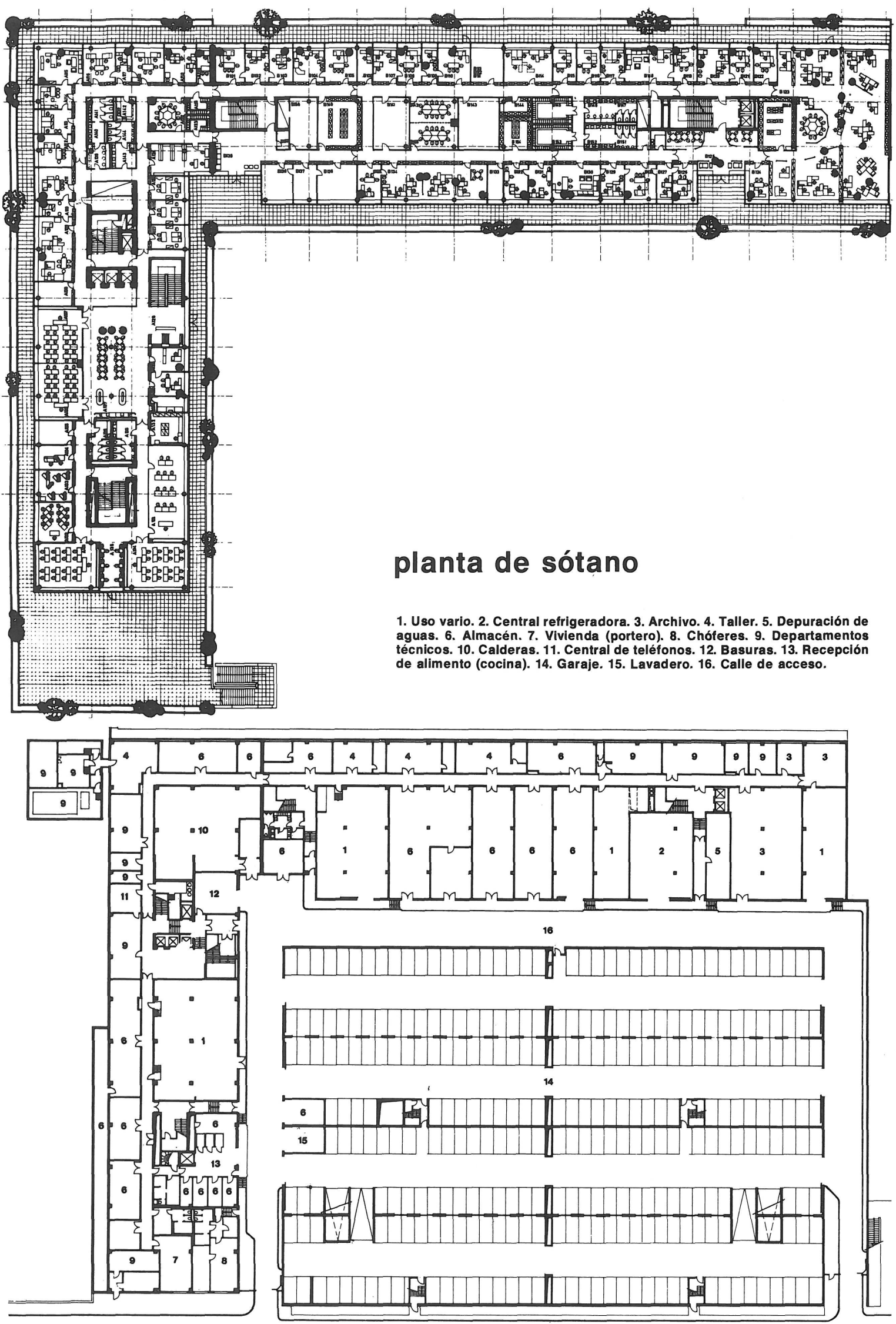




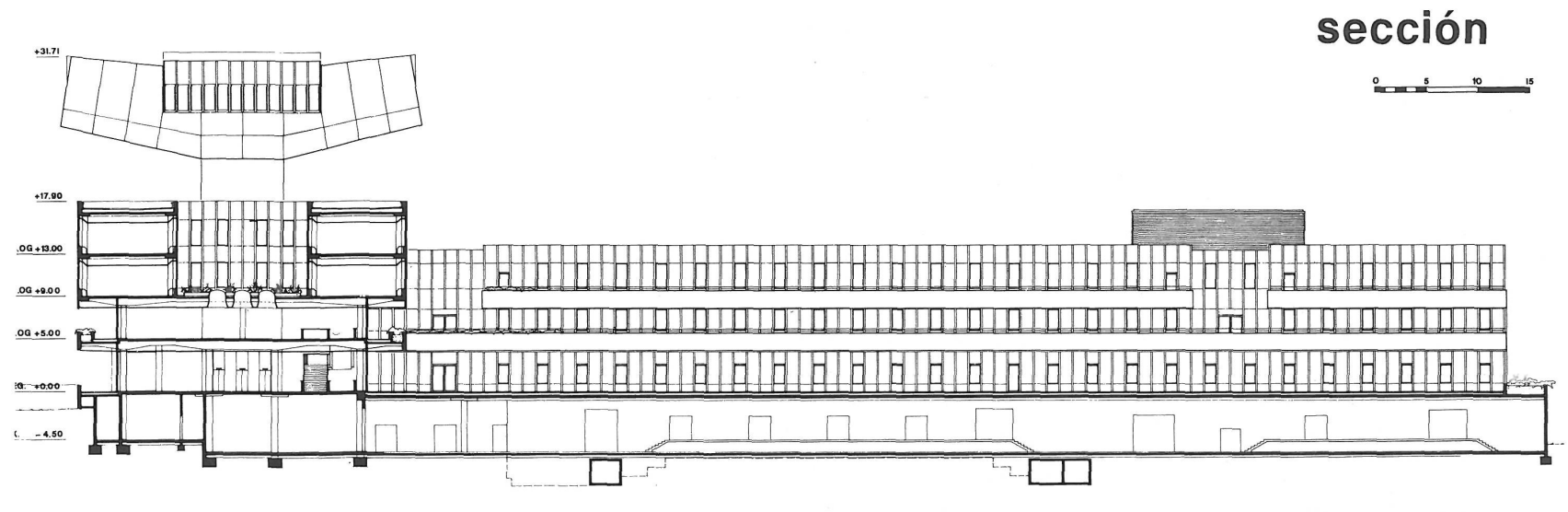

Interiormente el edificio cuenta, junto al vestíbulo de entrada en la planta baja, con restaurante y cafetería para clientes, así como numerosos despachos individuales dotados con los correspondientes servicios auxiliares: aseos, almacenes y comedor con cocina para las 800 personas de la plantilla. La cafetería atiende las necesidades de consumo en los lugares de trabajo. Todos los espacios interiores cuentan con una adecuada climatización.

Los aparcamientos subterráneos ocupan $12.700 \mathrm{~m}^{2}$ y proveen plazas de aparcamiento para 363 coches, a las que se suman las de superficie, situadas sobre el ala este del edificio y destinadas a los visitantes. Precisamente en este sector se podrá ampliar la construcción añadiendo un tercer brazo a la "L», rodeando el jardín central, y quedando perfectamente integrado en el conjunto.

Incluyendo la construcción sobre rasante, la edificabilidad resultante alcanza los 149.000 metros cuadrados.
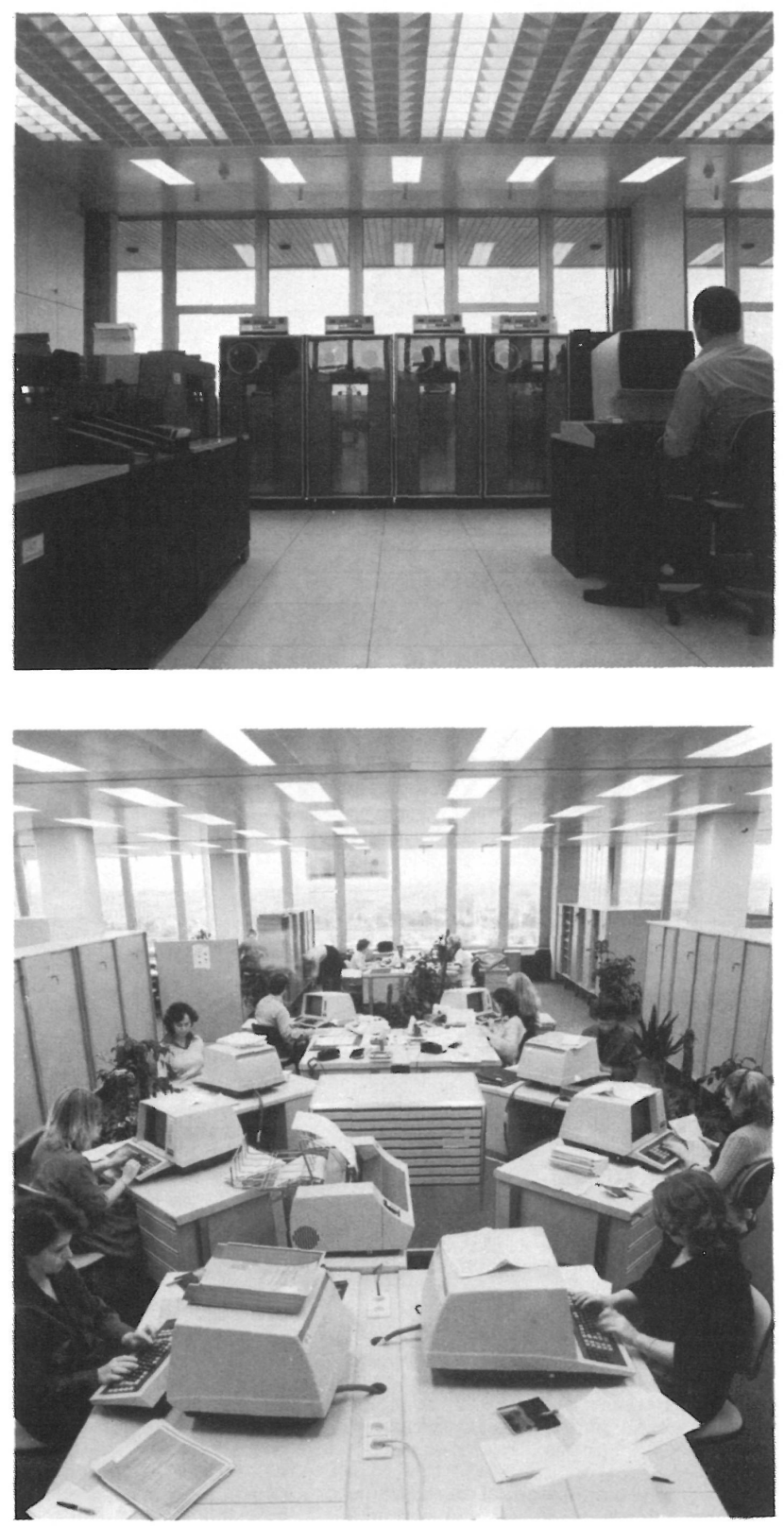

W. SCHMIDT 


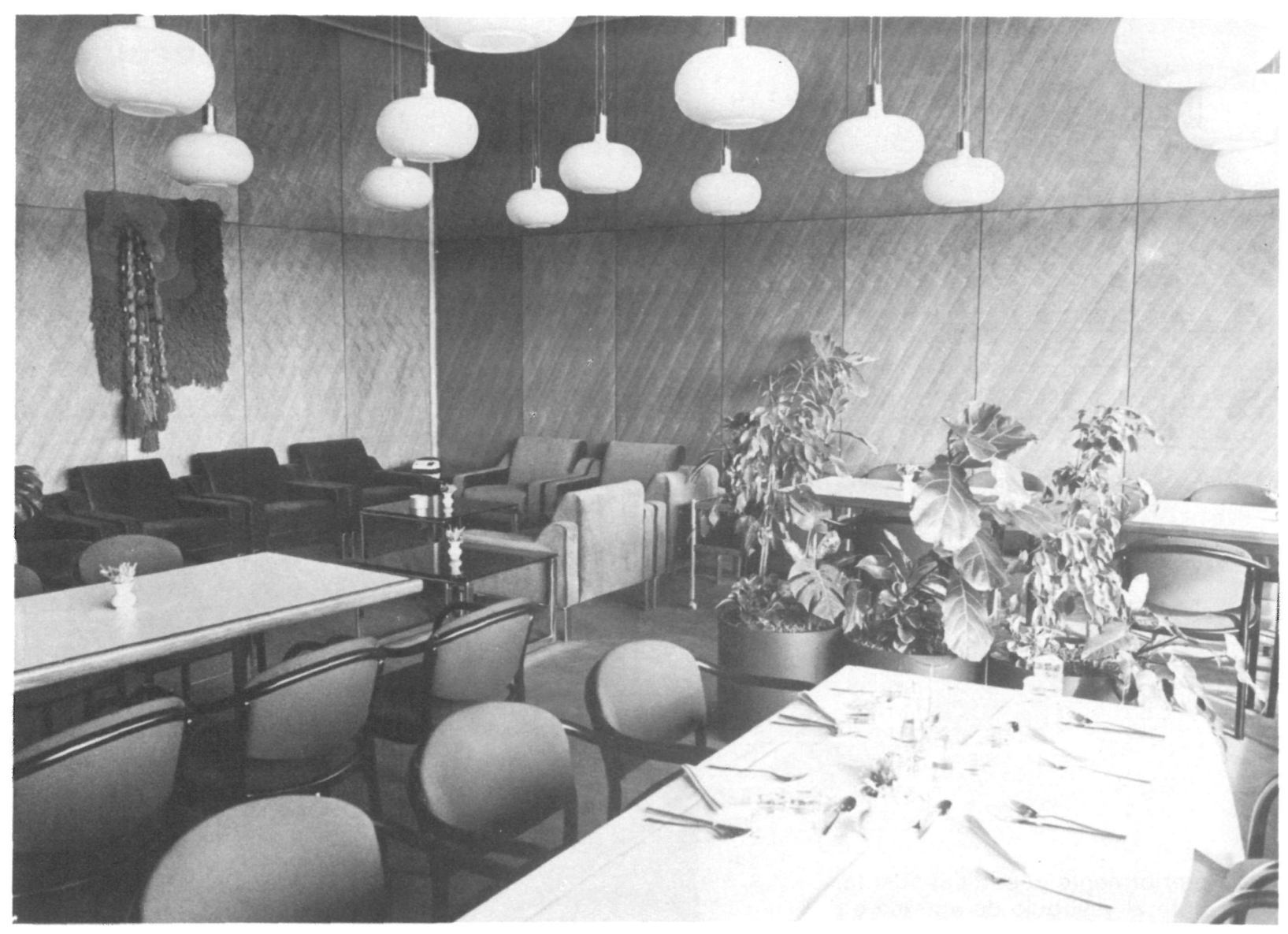

Fotos: Kristian Bissuti, Peterstrobl y O. J. Erwin Reichmann.

\section{résumé}

Edifice de bureaux, à Vienne. Autriche

Georg Lippert, architecte

Les bureaux centraux de l'Austrian Airlines se trouvent à proximité de Vienne, sur un grand terrain de $32.700 \mathrm{~m}^{2}$ dont les édifices construits occupent 13.000 le reste étant aménagé en jardins et esplanades.

L'édifice comprend queatre étages de hauteur maxima et un grand sous-sol abritant les services et un garage. Dans les étages supérieure se trouvent de nombreux bureaux, restaurant et cafétéria pour les clients ainsi qu'un réfectoire, avec cuisine, pour les 800 employés.

Du point de vue architectural on remarque la tour de $32 \mathrm{~m}$ de hauteur, conçue comme élément distinct capable de suggérer, à distance, la nature de l'activité de la compagnie.

\section{summary}

Office Building in Vienna, Austria

\section{Georg Lippert, Architect}

The main offices of Austrian Airlines are located in the outskirts of Vienna. in a large lot, $32.700 \mathrm{~m}^{2}$ in area, of which $13.000 \mathrm{~m}^{2}$ are lot, $32.700 \mathrm{~m}^{2}$ in area, of which $13.000 \mathrm{~m}^{2}$ are occupied by the building, while the remai-
ning surface are yards and landscaping.

The building consists of four stories above ground and an ample basement for carpark and services. The aboveground floors are distributed into numerous offices and rooms, plus a restaurant and coffee shop
for guests and mess hall for 800 employees for guests and $m$
and a kitchen.

Outstanding in the architectural design is a $32 \mathrm{~m}$-high tower conceived as a distinct element, symbolising and suggesting from faraway the nature of the company's activities.

\section{zusammenfassung}

Verwaltungsgebaeude in Wien . Oesterreich

\section{Architekt: Georg Lippert}

Die zentrale Verwaltung der Austrian Airlines belegt in der Nähe Wiens eine grosse Parzelle von $32.700 \mathrm{~m}^{2}$, davon nimmt der Bau 13.000 ein, während die restlichen freie Gelände und Gartenanlagen sind.

Das Gebäude besteht aus vier Stockwerken maximaler Höhe und einem geräumigen Kellergeschoss für Anlagen und Garagen. Die oberen Etagen sind in zahlreiche Büroräume, Restaurant und Cafeteria für die Kunden sowie Kantine und Küche für 800 Angestellte unterteilt

Aus der architektonischen Gestaltung hebt sich ein $32 \mathrm{~m}$ hoher Turm hervor, welcher als unterscheidendes Element gedacht ist und aus der Ferne bereits auf die Tätigkeit der Gessellschaft schliessen lässt. 